Etnográfica

Revista do Centro em Rede de Investigação em

Antropologia

vol. $23(2) \mid 2019$

Vol. $23(2)$

\title{
Entre a política e a técnica: prática jurídica no Supremo Tribunal Federal brasileiro
}

Between politics and technique: legal practice in the Brazilian Federal Supreme

Court

\section{Andressa Lewandowski}

\section{(2) OpenEdition}

Journals

Edição electrónica

URL: https://journals.openedition.org/etnografica/6706

DOI: 10.4000/etnografica.6706

ISSN: 2182-2891

\section{Editora}

Centro em Rede de Investigação em Antropologia

Edição impressa

Data de publição: 1 junho 2019

Paginação: 299-322

ISSN: 0873-6561

Refêrencia eletrónica

Andressa Lewandowski, «Entre a política e a técnica: prática jurídica no Supremo Tribunal Federal brasileiro», Etnográfica [Online], vol. 23 (2) | 2019, posto online no dia 24 junho 2019, consultado o 21 janeiro 2022. URL: http://journals.openedition.org/etnografica/6706 ; DOI: https://doi.org/10.4000/ etnografica.6706

\section{(c) (i) (8)}

Etnográfica is licensed under a Creative Commons Attribution-NonCommercial 4.0 International License. 


\section{Entre a política e a técnica: prática jurídica no Supremo Tribunal Federal brasileiro}

\section{Andressa Lewandowski}

O objetivo do artigo é analisar as decisões e as relações no Supremo Tribunal Federal brasileiro a partir dos conceitos locais de técnica, direito e política. Há no país uma ideia corrente de que a interferência de interesses políticos externos ao tribunal seria perniciosa e que suas decisões deveriam se pautar apenas pela técnica jurídica. O presente texto busca refletir sobre os modos como se faz política no direito a partir da prática jurídica apreendida etnograficamente na composição do tribunal, na gestão dos processos e nas relações entre os ministros e seus gabinetes. As decisões, as relações e os processos são tomados como objetos que não só modulam as direções da verdade como estabelecem as possibilidades de sua transformação.

PALAVRAS-CHAVE: antropologia do direito, política, prática, burocracia, supremas cortes.

Between politics and technique: legal practice in the Brazilian Federal Supreme Court - The purpose of this article is to examine the decisions and relations in the Brazilian Federal Supreme Court utilizing the local concepts of technique, law and politics. More than analyzing the decisions of the Supreme Court taking as a starting point the possibility of interference of political interests external to law, the goal of this article is to reflect on the ways that politics are made in the realm of law on the basis of a concept of legal practice seized in the composition of the court, the management of processes and the relationships between ministers and their offices. In this sense, decisions, relationships and processes are taken as objects that modulate the direction of truth and establish the possibilities of transformation.

KEYWORDS: anthropology of law, politics, practice, bureaucracy, Supreme Court.

LEWANDOWSKI, Andressa (andressapr@gmail.com) - Unilab-CE, Brasil. 


\section{INTRODUÇÃO}

Em 2000, Beverley McLachlin - a primeira mulher a assumir o mais alto cargo do sistema jurídico canadense - publicava um artigo no Singapore Academy of Law Journal intitulado "Judicial power and democracy", refletindo sobre a relação entre direito e política. O artigo explora aquilo que a autora chama de "fenômeno jurídico", ou seja, a potencialização do poder dos tribunais nas últimas décadas, não apenas no Canadá, mas no mundo todo. Os exemplos do fenômeno não são poucos e recupero aqui alguns. Na Austrália, a corte superior interfere - a partir de suas decisões - no debate político sobre direitos dos povos aborígenes. Em Israel, negocia conflitos entre diferentes grupos religiosos. Na Inglaterra, interfere no poder da primeira-ministra sobre a saída do Reino Unido da União Europeia. No Brasil, o Supremo Tribunal Federal tornou a união estável entre pessoas do mesmo sexo abrigada na mesma lei que protege uniões entre casais heterossexuais, cassou mandados de políticos, impede votações no congresso. Parece-me, portanto, relevante discutir política e direito, na medida em que, em contextos entendidos como democráticos, juízes estão tomando decisões consideradas políticas, isto é, posicionamentos a princípio reservados aos eleitos - no sentido literal da expressão. Por essa razão, proponho uma análise etnográfica sobre a relação entre política e direito a partir do caso da suprema corte brasileira.

A reflexão que proponho se dá a partir de um deslocamento analítico que, em vez de rastrear a convergência entre a prática jurídica e os interesses políticos externos a ela, tenta descrever a política própria do direito que se faz no cotidiano dos tribunais - e estou falando aqui especificamente do Supremo Tribunal brasileiro - nas (i) formas de gerenciamento dos processos e (ii) nas disputas em torno de posições no plenário. Tal não significa negar alguma influência política externa ao tribunal como um operador das decisões, mas compreender uma qualidade política no e do tribunal nos movimentos próprios da prática jurídica, ou seja, pensar política e direito a partir de outras das categorias e práticas que constituem o cotidiano do tribunal.

Ainda que juntar política e direito na mesma frase possa soar aos ouvidos dos juízes (chamados de ministros no Brasil) do Supremo Tribunal Federal (doravante STF) como uma acusação - tendo em vista que afirmam recorrentemente que seu trabalho é técnico e não político, negando insistentemente a política na técnica -, não é disso que se trata na análise aqui proposta. $\mathrm{O}$ argumento aqui apresentado não trata de evidenciar o processo conhecido como politização da justiça, tampouco o fenômeno de "judicialização da política" (Tate e Vallinder 1995) de que falávamos no início do texto. O que interessa aqui é pensar uma política que está na própria natureza do direito, ou seja, que tipo de política é produzido, reconhecido e efetivado naquele tribunal, ora como um dos aspectos da técnica, ora como forma de gestão de interesses jurídicos. 
Para tal, tomarei os processos de indicação, a gestão processual e a relação entre os ministros como três campos de relações em que podemos pensar a política e o direito como arenas diferentes e também como esferas não mutuamente excludentes. Em suma, técnica e política são formas distintas do que pode ser entendido como fazer política ou não fazer política.

Isabelle Stengers (2005) chama de "ecologia das práticas" o modo de pensar a ideia de prática a partir dos processos através dos quais ela se diferencia de outras e também de seus próprios processos de transformação. Segundo a autora, uma prática só pode ser alcançada se nos orientarmos por seus próprios requisitos - o que tem a ver com procedimentos de experimentação e, sobretudo, suas demandas -, que se relacionam, embora não se restrinjam, ao processo histórico em que tal prática é produzida. Essas duas dimensões formariam um conjunto de restrições que não apenas validariam ou legitimariam os atos ou as práticas, mas que, nos termos da autora, forçariam a própria ação/ atuação de seus praticantes (Stengers 1996: 74).

Uma ecologia das práticas tem menos a ver com ethos ou com sua inserção em estruturas hegemônicas "mais amplas" do que com registros daquilo que está sendo negociado para sua sustentação. A ideia de prática de Stengers (2005) situa-se entre a contingência do contexto e a vulnerabilidade da ação, porquanto nada está dado de início numa ecologia que se realiza em meio à multiplicidade de restrições e causalidades. Uma prática não deve ser, portanto, reduzida a uma mera função ou expressão de um ambiente, pois compõe, através das demandas e requisitos, o próprio bom operador.

Essa é umas das questões centrais do artigo aqui proposto: como se faz um bom juiz, um bom ministro, na modulação entre técnica, estética e política? A resposta a que procuro chegar analisa justamente esse "como se faz?", a partir das zonas de fronteira entre política e direito, ou, ainda, nas formas de fazer política, sem que isso seja visto pelos operadores como um tipo de vazamento e/ou ingerência do mundo da política na técnica do direito.

Se retomarmos um dos argumentos centrais dos trabalhos de Bruno Latour (2010) - refiro-me principalmente à etnografia no Conselho de Estado francês, mas não somente -, pode-se dizer que o Direito - assim com letra maiúscula como instituição é também política, na medida em que é um composto de elementos indefinidamente misturados que englobam, por exemplo, sua totalidade de textos, atos e instituições. Contudo, no argumento do autor, para ser ou se fazer direito é preciso que seja acionado um tipo de conexão específica que liga uma coisa à outra, a lei à decisão - um modo de enunciação extraído da instituição. Assim é o direito, com um modo específico de produção de verdade, com condições de possibilidade singulares. Desse modo, direito não é política. Assim afirmam também grande parte dos juristas com quem tive contato durante o trabalho de campo. O direito seria uma destas práticas, como a ciência e mesmo a política, que possuem modos de existência distintos 
e irredutíveis. Afastando-se da ideia de que o Direito teria uma essência transcendente e imutável, enraizada numa pressuposição abstrata (como defendia o jurista Hans Kelsen, base teórica de grande parte dos sistemas jurídicos de tradição civilista), Latour argumenta que a própria essência do direito está numa prática que se estabelece na relação entre enunciação e instituição.

Segundo Alain Pottage (2012), os regimes de enunciação se desenvolvem de acordo com princípios de uma engenharia discursiva que unem coisas tais como declarações, atos de fala e textos. O direito é definido a partir de um "marcador que qualifica determinados enunciados como um elemento de Direito e não de algum outro modo de existência" (Pottage 2012: 170). Para usar um termo comum entre os operadores do STF, trata-se de uma técnica - um modo particular de transmissão que coloca o texto em certo regime de inteligibilidade, em certo registro de conexão. Mais do que isso, parece possível argumentar que esses marcadores, que compreendem formas de argumentação como jurídicas, não estão prontamente dados, mas são produzidos a partir de uma gestão da legalidade (estou me referindo aqui exclusivamente à forma e não ao conteúdo), ou ainda de uma gestão daquilo que pode ser convertido em modo particular da operação jurídica; ou seja, a forma de um argumento ou de um tipo de técnica que podem ser compreendidos e aceitos como fazendo parte da prática jurídica não está dada a priori.

Antes de entrar de fato em tal "produção", faço uma pausa para localizar o Supremo Tribunal brasileiro em suas competências judiciais, assim como também localizar minha própria inserção no tribunal.

A Constituição Federal brasileira de 1988 delegou ao Supremo Tribunal Federal duas competências fundamentais: como cúpula do poder judiciário, funciona como última instância de todo sistema de justiça; como tribunal constitucional, detém a "precípua guarda da Constituição". Desse modo, compete ao tribunal julgar tanto "processos originários" - que começam e terminam no STF - como os recursos - em que o supremo pode reverter ou confirmar decisões já proferidas, quando estão de alguma forma relacionadas ao texto constitucional e não ao campo normativo infraconstitucional. De certa forma, pode-se dizer que qualquer processo jurídico que de alguma maneira discuta princípios e artigos da Constituição pode ser julgado pelo tribunal. Essa dupla competência - última instância do poder judiciário e tribunal constitucional levou o jurista português José Joaquim Gomes Canotilho, referência incontornável para o direito brasileiro, a afirmar, em entrevista ao jornal brasileiro Folha de São Paulo, que o STF seria um dos tribunais mais poderosos do mundo, por suas competências, mais amplas que as da Suprema Corte dos Estados Unidos ou de qualquer tribunal europeu. Foi nesse tribunal que realizei pesquisa etnográfica entre os anos de 2011 e 2013. Minha pesquisa de campo percorreu, assim como uma ação jurídica, uma série de instâncias no interior do STF, acionando diversas autorizações para cada parte da pesquisa. Durante o tempo 
da pesquisa frequentei tanto os julgamentos como os gabinetes dos juízes e os setores administrativos. A pesquisa de campo envolvia observação e entrevistas com funcionários e ministros, além de pesquisa documental com e nos processos. Parte dos dados analisados nesse artigo é proveniente de entrevistas com funcionários, ministros, advogados e observações de campo, mas também se referem ao modo como o STF aparece em outras instâncias, como jornais, comentários de políticos, sabatinas no Senado Federal (públicas e transmitidas pela STF Senado).

Diante disso, consideremos como ponto de partida as indicações dos ministros, um dos efeitos da série de outros processos que pretendo descrever.

\section{AS INDICAÇÕES COMO PRIMEIRO EFEITO}

As indicações dos ministros do STF brasileiro podem ser tomadas como uma primeira questão para análise, dado que demandam dos futuros ministros ou candidatos a vagas no STF um tipo de atuação política que os coloca em outro registro de relações, diferentes daquelas usualmente estabelecidas como sine qua non no mundo jurídico brasileiro. Os comandos constitucionais brasileiros para a escolha de um ministro do STF estão no artigo 101. ${ }^{\circ}$ da Constituição Federal, que declara que o Supremo Tribunal se compõe de 11 ministros, entre cidadãos com mais de 35 anos e menos de 65 anos e que possuam "notório saber jurídico e reputação ilibada". São escolhidos pelo presidente da República e aprovados pelo Senado Federal. ${ }^{1}$ Mas quem de fato diz ou reconhece esses critérios - mais do que o presidente e os senadores - são aqueles que integram uma complexa rede de diferenciação própria ao universo jurídico brasileiro. Reputação e notório saber são, portanto, efeitos dessa rede, de seus modos de instanciação e constituição, ou seja, efeitos de como no interior do universo jurídico se reconhecem qualidades que tornam alguns juristas indicáveis para os cargos nos tribunais superiores.

Poucos ministros comentam seus próprios processos de indicação. ${ }^{2}$ Talvez exatamente porque a indicação coloca em evidência um qualificante reconhecidamente político - que insere os futuros ministros em posição vulnerável da qual, depois de empossados, esforçam-se por se afastar rapidamente. Alguns dos ministros que entrevistei falavam da surpresa de terem seus nomes avaliados pelo presidente da República. Contudo, juízes ou advogados que manifestam

1 A regra brasileira é a mesma das nomeações para a Suprema Corte dos Estados Unidos, ainda que existam diferenças fundamentais, em especial no requisito de aprovação pelos senadores.

2 Dos sete ministros que entrevistei durante o trabalho de campo, apenas três deles me contaram todo o processo de indicação, ou seja, quem articulou a chegada de seu nome à presidência da República, como foi a preparação para a sabatina no Senado Federal, etc. Mesmo em entrevistas concedidas a jornalistas, o tema da indicação sempre aparece de modo implícito. 
a vontade de assumir o cargo de ministros do STF reconhecem "fazer mais" do que construir seus currículos e se preparar para eventualmente terem seu notório saber reconhecido e serem chamados a cumprir a "missão" (expressão por eles utilizada) de julgar, sentados nas poltronas da suprema corte.

A indicação de um ministro é, mesmo que de modo velado, amplamente entendida como uma escolha política. Se isso explicasse qualquer coisa, poderíamos parar por aqui, mas certamente não é o caso. Por um lado, é uma escolha política simplesmente porque é uma decisão do presidente, que avalia o melhor nome diante da conjuntura, por sua vez determinada por uma série de fatores que não apenas a facilidade ou dificuldade da aprovação do nome pelo conjunto de senadores. É também uma escolha política tendo em vista a importância do cargo e as possíveis implicações na política nacional das decisões que sejam tomadas. Particularmente no caso brasileiro, não existe clareza sobre as posições ou alinhamentos políticos de grande parte dos indicados, poucos os expõem publicamente. O que se torna público são especulações da imprensa nacional e dos partidos políticos em torno do nome e dos possíveis posicionamentos futuros do ministro. Diante das indicações, os políticos estão avaliando os riscos das posições jurídicas dos futuros indicados. É uma avaliação difícil, tendo em vista que operar o direito - ou fabricar o direito, para usar o termo de Latour (2010) - não é uma operação simples que conecta as leis aos fatos ou os fatos às leis; essa operação exige, sobretudo, uma transformação continuada tanto das leis como dos fatos, operação essa sintetizada pela expressão corrente no STF: a Constituição é o que os ministros dizem que ela é.

Quando uma vaga no supremo é aberta, na maioria das vezes por aposentadoria compulsória aos 75 anos, vários nomes de juristas são "ventilados", expressão utilizada em referência aos nomes aptos a serem indicados pelo chefe do poder executivo. Esses nomes que figuram nas listas de "candidatos" devem ostentar algumas qualidades, cumprir um tipo de gabarito que torne sua indicação possível e viável. Nem sempre o "notório saber jurídico" é o único critério a prontamente delimitar um pequeno conjunto de nomes. Dentre essas qualidades, uma delas ganha importância: ser uma indicação técnica. Um ministro ou futuro ministro considerado técnico, tanto por seus pares como por políticos que irão aprovar seu nome no Senado Federal, consegue acionar um tipo de garantia de independência em suas decisões que facilita a aprovação de seu nome e também garante uma posição mais confortável na dinâmica interna do próprio tribunal. Esse critério que identifica os indicados como sendo técnicos está relacionado a vários elementos da trajetória de cada um deles, em especial a parcimônia das relações com partidos políticos.

Em uma recente publicação - um caderno de curiosidades editado pelo ministro decano do STF Celso de Mello - podemos encontrar alguns indicadores dos critérios das indicações: 
"Desse total (287 Ministros), compreendidos ambos os períodos históricos [Império e República], todos os Ministros - exceto os Ministros Néri da Silveira, Cezar Peluso, Eros Grau, Cármen Lúcia e Menezes Direito - graduaram-se, no Brasil, por Faculdades públicas de Direito.

No Império, as Escolas de Direito que forneceram os Juízes para o Supremo Tribunal de Justiça foram as de Coimbra, de São Paulo (Faculdade de Direito do Largo de São Francisco) e de Olinda/Recife" (Mello 2012: 27).

A tese de Frederico Normanha Ribeiro de Almeida (2010), cientista político brasileiro, já demonstrou o papel de algumas universidades na formação das elites jurídicas no país. Segundo o autor, existe uma hierarquia dos diplomas das faculdades de direito responsáveis pela formação dos estratos inferiores e superiores daqueles grupos profissionais. Essa hierarquia estaria de acordo com a conformação da maioria dos cargos do chamado sistema de justiça. No Brasil, a Universidade de São Paulo formou grande parte dos juristas consagrados pela doutrina, assim como nos Estados Unidos esse papel está reservado às universidades de Harvard e Yale.

Certamente, o lugar de formação tem um peso na indicação, mas não parece ser atualmente o fator mais relevante; tampouco a relação se dá exclusivamente por conta de uma possível melhor formação. Os modos de diferenciação que compõem o universo do direito são tanto mais complexos quanto menos diretos, ou seja, não se trata apenas de mérito, mas de relações.

Se um diploma de uma universidade prestigiada pode ser um critério na indicação, ele deve ser acompanhado por vários outros. Determinados lugares no interior do sistema de justiça possibilitam que um nome seja cogitado para uma vaga na corte. Em entrevista a mim concedida durante a pesquisa no STF, o ministro Luiz Fux ressalta alguns deles. ${ }^{3}$ Segundo o ministro, é comum que desembargadores do Tribunal de Justiça do Estado de São Paulo figurem nas listas que chegam até a presidência. Ainda segundo o ministro Fux, os estados da federação têm vagas em determinadas composições do supremo tribunal. No caso da sua indicação, ele afirma que "tentou bastante". Na primeira vez conta ele -, a vaga supostamente pertenceria ao Rio de Janeiro, seu estado de nascimento, mas o indicado foi o ministro Menezes Direito, também ministro do Superior Tribunal de Justiça (STJ), assim como ele, porém "mais antigo".

Nesse caso, dois critérios operaram juntos: o primeiro, ser o ministro do estado do Rio de Janeiro, e o segundo, ser proveniente de um tribunal superior, o Superior Tribunal de Justiça. Tribunais superiores como o STJ ou o Tribunal Superior do Trabalho (TST) tradicionalmente têm alguns de seus membros indicados ao STF como "candidatos naturais". Com a morte do ministro 
Menezes Direito, a vaga do Rio de Janeiro e do STJ ficou em aberto, podendo o ministro Fux "concorrer" novamente. Nessa segunda tentativa, "queriam uma mulher"; me disse o ministro, foi escolhida, então, a ministra Carmem Lúcia. $\mathrm{Na}$ próxima vaga aberta, seu nome pôde finalmente ser considerado para a disputa.

Para "concorrer", o futuro ministro precisa buscar apoio, formando listas com assinaturas de políticos, magistrados e advogados prestigiados, que serão enviadas a representantes do poder executivo. Costumam também reunir-se com ministros de Estado, em especial com o ministro da Justiça, para se "colocarem à disposição". É dessas reuniões que saem as outras listas que serão encaminhadas ao presidente da República.

O apoio de pessoas tidas como "influentes" dentro do poder executivo ajuda muito um candidato à vaga no STF, ao mesmo tempo que coloca o futuro candidato em situação desconfortável. Como me dizia um dos funcionários do STF, "é preciso que o ministro tenha cautela nessa busca de apoio, porque o que seria uma atuação normal é sempre usado para acusá-lo de fazer promessas a partidos ou políticos". Uma das formas de "cautela" é que sejam os advogados apoiadores aqueles a buscar os apoios de deputados, senadores e governadores. O candidato apenas se reuniria com as figuras de "maior peso", ou seja, mais influentes na indicação. Certamente isso não é uma regra que vale para todas as indicações, mas um tipo de modelo e resguardo a ser observado.

Diz-se também que os governadores dos estados federados, especialmente os aliados políticos do governo federal, mas não exclusivamente, "fazem campanha" nas indicações, tentando assegurar vagas, dando a entender que se supõe serem os ministros, em alguma medida, representantes de suas regióes mais do que representantes de determinadas posições jurídicas ou políticas.

Um dos exemplos mais recentes é a indicação do ministro Edson Fachin. Sua possível indicação fez com que diversos jornais publicassem matérias com sua biografia, situando o ministro como aliado ao Partido dos Trabalhadores - considerado um partido de esquerda e, à época, o partido da presidente -, supostamente defensor das ocupações de terra realizadas pelo Movimento dos Trabalhadores Sem Terra e da legalização do aborto. Ainda assim, o futuro ministro contou com o apoio fundamental do governador de seu estado de origem, assim como dos senadores paranaenses filiados ao partido de oposição ao governo federal. Em defesa do candidato, um dos senadores da oposição declarou: "Ele é candidato a juiz e não a uma vaga na política; o que deve importar é que seja um candidato técnico". Nesse sentido, tanto juristas como políticos reafirmam e entendem haver uma separação que deve ser marcada.

Ser um candidato técnico, ou pelo menos ser reconhecido como tal, permite ao indicado ultrapassar uma fronteira mais ou menos delineada entre a política como jogo de interesses e a técnica como pura "aplicação" da lei. Técnica e política ganham aqui uma primeira separação, que tanto evoca uma distinção 
moral entre política e direito como reforça a ideia de que se trata de coisas ou campos distintos com suas próprias formas de regulação. Ao mesmo tempo, é justamente quando um candidato pode ser considerado técnico que ele alcança uma posição política que pode garantir o trânsito entre esses dois domínios.

A Procuradoria-Geral da República (representantes do Ministério Público), assim como a Advocacia-Geral da União (advocacia do poder executivo), também são celeiros de nomes sempre lembrados nas listas que chegam à presidência. Na composição atual da corte, três ministros vieram do Ministério Público, tendo dois deles ocupado o cargo de Procurador-Geral da República, e dois outros ministros foram advogados da União. Nesses últimos casos, a escolha tem pouco a ver com a indicação em si, mas, sobretudo, com a atuação dos futuros ministros.

Procuradores e advogados públicos ou privados, quando indicados, são alçados ao cargo de juízes. Existe aqui uma transformação que, aos olhos leigos, parece pouco significativa, mas que para o mundo jurídico carrega uma marca: passam para "o outro lado do balcão", como se costuma dizer no Supremo Tribunal. Ou seja, se antes ocupavam a tribuna como defensores ou acusadores, assumem, com a indicação, outro papel no sistema de justiça. Essa diferença significativa é vista entre os ministros e servidores do tribunal como positiva, pois carreiras jurídicas diferentes permitem uma pluralidade de "sensibilidades jurídicas”. Nos termos locais, dinamizam-se os paradigmas de decisões. Dizem também os funcionários que experiências diversas, não só jurídicas como também políticas - ou seja, do mundo da política -, trazem ao tribunal um tipo de expertise necessária ao bom andamento processual e às boas relações entre os três poderes da República.

Ainda que a finalidade da abertura da composição do tribunal a diversas carreiras jurídicas seja a diversidade de experiências, quando um ministro toma posse, o que se espera é uma conversão, um tipo de alinhamento ontológico. Explico. Certa vez o ministro Celso de Mello, decano da corte, afirmou em um julgamento que advogados, promotores e juízes são "ontologicamente" diferentes. Durante entrevista com o hoje ministro Luís Roberto Barroso, em determinado momento ele me disse: "Eu tenho alma de advogado". Não o entrevistei depois da posse, mas acompanhei alguns de seus primeiros julgamentos. Recordo-me de que algumas vezes, especialmente quando o então novo ministro mostrava preocupação com os advogados da tribuna, tentando encaminhar alguma questão para facilitar o trabalho de seus antigos colegas, era prontamente lembrado por seus pares de que não era mais advogado.

Uma nomeação para o STF acionaria uma passagem a outro tipo de ontologia, nos seus termos, que me parece significar outro tipo de perspectiva sobre as causas e os processos, outro tipo de relação com causas e pessoas que deve ser marcado por um tipo de "estética". O uso do termo se relaciona com a definição stratherniana, que evidencia a capacidade de adequação e a força 
de persuasão das formas (Strathern 1991), sendo as formas a que me refiro agora as formas de relação. Nesse sentido, a forma das relações entre os agentes processuais deve estar precisamente delimitada, pelo menos no momento do julgamento plenário: a forma pública do processo.

Diversas posições nos processos não devem ser confundidas, sob pena de suspeição das decisões do tribunal. Ainda que no Brasil não operem as classificações de advogados que operam nos sistemas da Common Law, em especial as classificações dos advogados que aparecem no Reino Unido - me refiro à diferença entre barristers e solicitors -, existem classificações que garantem a uma parcela dos advogados e juízes a condição de "juristas" - que não funciona como termo genérico, mas identifica advogados - ou juízes - influentes política e juridicamente, na medida em que são considerados mais do que operadores do direito, mas, sobretudo, pensadores do direito. As grandes causas que passam pelo STF envolvem esses nomes que compõem o que se costuma chamar de elite jurídica brasileira.

Mais recentemente, as indicações levam em conta o enfrentamento das desigualdades de gênero e o racismo, bastante evidentes nos tribunais superiores brasileiros. A primeira mulher a ser indicada para ministra do STF foi Ellen Gracie, nomeada em 2001; o primeiro negro, o ministro Joaquim Barbosa, foi indicado em 2003.

Quando as listas com os nomes qualificados chegam até a presidência, alguns nomes são selecionados para uma entrevista, realizada primeiro com o ministro da Justiça, e depois com a/o presidente. A trajetória do ministro Luís Roberto Barroso, descrita por ele durante a sabatina (entrevista) no Senado Federal, destaca esses momentos em que os candidatos são arguidos. Disse o ministro:

"Eu não sei exatamente como eu cheguei aqui, senador. Eu verdadeiramente não tinha uma articulação política relevante. Eu fiquei muito honrado, muito feliz e muito surpreso. Geralmente, quando meu nome aparecia em alguma disputa, em alguma vaga para o Supremo, o sujeito que ia dizia que estava disputando comigo. Porque eu era o que não tinha nenhuma chance. Eu verdadeiramente fui pego de surpresa. Eu vou dizer para o senhor com absoluta honestidade as pessoas que em algum momento falaram comigo sobre esse assunto. $\mathrm{O}$ ex-parlamentar e meu amigo de nome Sigmaringa Seixas me disse: 'seu nome é um dos nomes que a presidenta está considerando'. O ex-secretário da Casa Civil, Dr. Beto Vasconcelos, foi uma pessoa que mais de uma vez me disse: 'seu nome é um nome que gostaríamos de ver no Supremo'. Mais proximamente do desfecho, o ministro José Eduardo Cardoso conversou comigo, e depois a presidenta da República me convocou. Eu estive no Palácio do Planalto levado pelo ministro da Justiça. Conversamos por aproximadamente uma hora, ela me fez uma sabatina 
inteiramente republicana. Não me perguntou sobre nenhuma questão específica. Me perguntou sobre separação de poderes, questões sobre conflitos federativos. Conversamos sobre royalties. Ela me perguntou a posição que eu defendia para o Rio de Janeiro. Portanto, tivemos uma conversa republicana. Depois, na semana seguinte, ela me chamou pela segunda vez, conversamos uns 15 minutos sobre generalidades, e ela me fez o convite". ${ }^{4}$

Embora secretas, algumas dessas reuniões são noticiadas pela imprensa, que passa a afirmar que determinados nomes serão os escolhidos. No entanto, ironicamente, na maioria das vezes que um nome sai na imprensa como certo, outro nome é de fato indicado. Alguns dos funcionários do tribunal com quem conversei durante processos de indicação me dizem que o próprio executivo "soltava" alguns indicados para a imprensa, de modo a "testar" a facilidade ou a dificuldade de sua aprovação.

Outro fator relacionado à indicação é a própria composição do tribunal. As cadeiras vagas têm nome e algumas vezes têm perfil. Em alguma medida, a nova indicação deve manter certo equilíbrio no tribunal. Esse equilíbrio é apreciado a partir das supostas diferentes técnicas jurídicas de quem sai e de quem entra, as quais permitem uma classificação dos juízes como "conservadores" ou "progressistas" (liberais), ainda que essa classificação seja sempre provisória e sujeita à própria dinâmica interna de produção de decisões e da relação entre os juízes. Para esse suposto equilíbrio, o currículo dos ministros ganha importância. Se foram juízes, o histórico de decisões tomadas pode ser analisado, assim como a atuação dos procuradores e advogados.

Quando finalmente indicados - processo que pode levar de dias a meses -, seus nomes são entregues ao Senado Federal, que irá realizar a chamada sabatina, que acontece antes da votação em plenário. Esse momento, de sabatina, antes entendido como mera formalidade, exigiu mais recentemente dos candidatos um preparo "político", tendo em vista que políticos contrários à indicação tentam constranger o candidato com a possibilidade da não aprovação do nome. De fato, na história recente, nenhum nome foi barrado pelo Senado, ainda que diversas vezes a ameaça tenha sido declarada.

Quando nomeados, o costume é que o novo ministro receba de presente de seus apoiadores a toga que irá usar nos futuros julgamentos. Algumas delas são herança de outros ministros ou juízes. Também escolhem o nome pelo qual preferem ser chamados no tribunal. Já empossados, independentemente de sua experiência ou de seu "notório saber jurídico", serão ainda "novatos", devendo respeito tanto ao tribunal e à sua história, quanto aos ministros mais antigos e sua autoridade já consolidada. A antiguidade é talvez o critério que mais opera

4 Ver transcrição da sabatina realizada pelo ministro em 2013, disponível em < http://www.senado. leg.br/atividade/comissoes/sessao/disc/disc.asp?s=000387/13 > (última consulta em junho de 2019). 
nas relações estabelecidas, tanto entre ministros como entre os funcionários do STF.

A indicação do presidente da República mobiliza, portanto, todos os critérios apresentados. Esses critérios compõem a política da política, mas também, e sobretudo, a política do direito. Nenhum presidente indica um nome completamente desconhecido do universo jurídico. Os ministros são, em certa medida, efeitos desses critérios, do aval de seus pares, do lugar em que atuam, da faculdade em que estudaram. Embora o processo de indicação, em grande parte das vezes, exija uma atuação política dos candidatos, já depois de empossados os ministros promovem um afastamento estratégico do processo de sua indicação, insistindo que o direito é técnica.

Contudo, como veremos na próxima seção, mesmo a técnica guarda sua própria política, acionada na estética das relações entre os ministros e entre os processos. Nessa medida, enquanto nesse primeiro momento a política aparece como uma forma de articulação necessária e ao mesmo tempo a ser obscurecida de modo que apenas a técnica reste como fio condutor de uma indicação que envolve agentes externos ao tribunal, política e técnica, a partir de agora, passam a operar as relações internas ao tribunal, o modo como as decisões podem ser articuladas a partir das formas de gestão das relações entre os ministros e dos ministros com as causas, ou ainda, a estética das relações e a política dos processos.

\section{UMA ESTÉTICA DAS RELAÇÕES}

Os registros históricos do STF dão conta de sua criação em 1891, durante a vigência da primeira Constituição republicana brasileira. Embora o atual STF seja diferente daquele tribunal de mais de 100 anos atrás, quer nas atribuições, quer na composição, existe uma ideia recorrente de tradição nas falas dos ministros. Essas tradições dizem respeito, principalmente, ao modo de atuação de seus ministros e funcionários na resolução de questões, especialmente as mais conflituosas, e também à relação do tribunal com os demais poderes da República. Ainda que a ideia de tradição seja sempre reposicionada e reinventada: o que é tradicional ou aparece como tal nem sempre é a mesma coisa; a continuidade certamente é uma marca de valor observada pelos ministros, mas é uma continuidade que incorpora o descontínuo (as mudanças necessárias), como se estivesse o tempo todo, na sugestão de Pottage, "em ambas as extremidades do contínuo" (2004: 9, a respeito de Strathern) - ou seja, quanto mais tradição, mais modernidade.

Um dos efeitos dessa "tradição" deve ser observado principalmente pelos ministros mais novos, pelo menos durante o tempo em que "pagam pedágio" expressão dos funcionários antigos do STF que se refere a um tempo em que os novatos devem permanecer na sombra dos mais antigos (e mais antigos aqui 
envolve até os que já não estão no tribunal, pois, uma vez ministro, sempre ministro; é um cargo que não se perde, e aqueles que se aposentam são chamados de "ministros de sempre"). Existe um comprometimento dos ministros com uma prática pretérita que mobiliza sua atuação presente. É possível então, por conta de tais vínculos, que a posição jurídica ou política de um ministro não seja evidenciada em seu voto nos primeiros processos em que irá votar.

Além disso, um bom ministro ou um bom advogado de tribunal superior seria também definido por seguir de modo mais ou menos fiel esse conjunto de tradições/práticas do tribunal. Ainda que essas práticas não sejam totalmente estabilizadas, é preciso um esforço para não revelar algum rompimento, ou um dissenso capaz de constranger posições diferentes.

As restrições dos ministros mais novos são rapidamente observadas nos julgamentos: frequentemente interrompidos em seus votos, raramente interrompem outros colegas. Também não é comum que um ministro recém-chegado inaugure uma divergência com alguma jurisprudência já consolidada do tribunal. O costume é que se alinhem à corrente majoritária na votação, como se fosse necessário um tempo de experiência para incorporar as práticas, até que possam travar um debate com os demais ministros.

Como esclarece o ministro Luiz Fux:

"Quando um ministro chega a um colegiado, a tendência é acompanhar a jurisprudência consolidada, que normalmente está nos votos majoritários. Você pode eventualmente ressaltar um ponto de vista, mas a tendência é acompanhar. Você não pode chegar a um colegiado tentando mudar tudo. Eu aprendi que o convívio no colegiado é assim". 5

Essa posição é também estratégica, na medida em que se sabe que uma mudança de jurisprudência ocorre lentamente, a partir de pequenas "ressalvas". Qualquer posição diferente dessa tradicionalmente observada pelos novatos sofre retaliações dos ministros mais antigos. O "convívio no colegiado" exige certo "jogo de cintura", que permite ou não aos juízes sustentar alguma posição. Mesmo entre os mais antigos, abrir a divergência em casos tidos como irrelevantes não parece ser adequado para a dinâmica do colegiado. A fim de fazer ou compor a maioria e ser acompanhado pelos colegas em processos importantes, seria preciso saber perder e recuar em alguma outra posição.

Há também alguns juízes que sentem certo desconforto em ocupar a posição de voto vencido ao declararem um voto isolado da maioria, ou seja, não acompanhado por nenhum outro ministro. Conforme me disse o ministro Luís Roberto Barroso, alguns ministros, quando percebem a tendência do colegiado, 
podem mudar seu voto, tendo em vista que ficar vencido seria um ônus que, a depender do caso, "não valeria a pena". Não valeria a pena pela possibilidade de alianças futuras e também porque uma decisão proferida por um plenário dividido deixaria sempre alguma questão em aberto, como se perdesse um pouco de sua eficácia (o que pode ser estratégico em alguns casos mais do que noutros). Neste caso, trata-se menos de um receio individual do que de uma preocupação em preservar os fundamentos da "casa".

Segue outro trecho da entrevista com o ministro Fux, no qual identifica outra apreciação possível do voto contracorrente:

"Às vezes eu fico vencido e fico satisfeito com o que eu propus; mas eu não tenho por hábito ficar vencido. Quando fico vencido não me abalo, mas não tenho por hábito, não. O ministro Marco Aurélio pode falar melhor sobre isso. Ele acha que a beleza do colegiado é o voto vencido. Um voto vencido isolado é ruim, não tem beleza nenhuma. Um voto vencido é ir contra o voto da maioria e depois ter de [se] submeter ao colegiado. Tem de saber viver em colegiado; se o melhor para o país o colegiado acha que é aquilo, vamos embora, vamos adotar a posição". ${ }^{6}$

A disputa de posição poucas vezes acontece em casos mais "comuns"; ao contrário, são os casos tidos como de maior impacto que mobilizam o debate entre os ministros, com destaque para a especificidade dos julgamentos plenários, que, no Brasil e diferentemente da maioria dos países da Europa e Estados Unidos, são públicos e televisionados. Se as disputas mais acirradas no plenário são exceções, existe uma disputa sutil, ou quase sempre sutil, que opera no que chamo aqui de "lógica dos constrangimentos". O uso dos precedentes nos votos é uma das formas que ela assume. Citar como precedente uma posição anterior de um ministro presente no julgamento - ainda mais se o ministro citado for considerado uma autoridade em determinado assunto, ou seja, um especialista na área do direito que está sendo debatida - o constrangeria a seguir a mesma posição ou, pelo menos, a justificar uma eventual mudança de posicionamento.

Conforme algumas entrevistas e as observações dos julgamentos, há no plenário alguns ministros considerados como lideranças. São identificados como aqueles que falam mais e falam sempre. Às vezes levantam a voz, expondo seus argumentos de modo mais enfático; têm a capacidade de "falar sem serem interrompidos" (Souza 2012: 112), embora sejam eles a interromper os demais ministros quando estão a proferir seus votos.

Acompanhei, durante o trabalho de campo, a entrada de três novos ministros. Conversando com alguns funcionários do tribunal, com os quais 
mantinha contato frequente, constatei que havia sempre entre eles uma expectativa de como se comportaria o novo ministro diante dos ministros mais antigos. Certa vez, um deles me disse: "Acho que esse ministro novo vai ser importante, não vai se impressionar com quem levanta a voz no plenário. Se determinado ministro conhece direito alemão, se sabe muito, esse novo que vem aí tem até mais conhecimento".

A "demonstração de domínio da competência judicial" (Souza 2012: 113) é um diferencial que coloca alguns dos ministros em posição considerada como de liderança e autoridade. Contudo, como demonstra Souza (2012), a autoridade dos ministros pode variar a cada processo, a depender da matéria em julgamento. Por essa razão, ainda que alguns votos sejam considerados mais relevantes do que outros em determinadas matérias e que alguns ministros tenham maior capacidade de influência nos votos dos demais, não é possível localizar alianças permanentes no plenário. O que parece existir são alinhamentos contingenciais, de acordo com cada processo. Sendo assim, é possível afirmar que não existe apenas um direito, embora haja uma "prática compartilhada" entre as diversas áreas do direito. Essas áreas de especialidade ou subdivisões do conhecimento jurídico implicam posições diferentes dos ministros. Um ministro considerado liberal, ou "garantista" em seus votos em matéria de direito penal, pode ser conservador em outras áreas do direito, por exemplo. Em suma, as posições jurídicas de cada ministro podem mudar de acordo com a área do direito debatida em cada processo.

Aqueles que são considerados especialistas em determinada matéria carregam um tipo de lastro, evidenciado no voto e na quantidade de vezes em que são citados pelos colegas. Para abrir divergência com um ministro nessa posição seria preciso avaliar o risco do próprio constrangimento.

Não existem no tribunal espaços de discussão entre os ministros que não sejam os espaços de julgamento, nas turmas ou no plenário. ${ }^{7}$ A rigor, os ministros não discutem seus votos com os colegas antes dos julgamentos, apenas trocam impressões com seus pares enquanto esperam, no salão branco - espaço ao lado do plenário. Seria o espaço do julgamento o lugar privilegiado para o debate e, para tal, se espera dos magistrados comedimento na argumentação e na contra-argumentação. Seria preciso saber discordar de um voto, não negando ao posicionamento contrário a possibilidade de ser considerado correto sob outra perspectiva, ou seja, garantindo a pluralidade de posições.

A conversa entre ministros antes dos julgamentos é malvista pelos colegas, que entendem que existe alguma posição sendo articulada da qual não fazem

7 O Supremo Tribunal brasileiro é composto por duas turmas, formadas por cinco ministros cada uma (o presidente do STF não participa). Nesses pequenos colegiados são julgados alguns processos que chegam à suprema corte e que não demandam a declaração de inconstitucionalidade de leis, o que compete somente ao plenário. Se julgam nessas turmas, especialmente, pedidos de habeas corpus. 
parte. Os funcionários mais antigos do STF dizem que o tribunal funciona em "ilhas que trocam processos", mas com pouca conexão. Na realidade, o que me pareceu é que as divergências de posição entre os ministros e seus gabinetes conformam um tipo de disputa que se dá na relação entre os gabinetes, muito mais do que entre os ministros. ${ }^{8}$ De todo modo, quando existe uma questão "complexa", as conversas podem acontecer, desde que com a discrição necessária. A posição dos colegas é avaliada, sobretudo, na análise dos votos que os ministros costumam dar em determinadas matérias; essa é a medida da temperatura do plenário, que pode ou não permitir o debate de determinado processo.

O conhecimento da dinâmica dos votos e das relações entre ministros faz também "bons" juízes: aqueles que têm o conhecimento técnico necessário e detêm a expertise que permite que suas posições se movimentem no tribunal, a partir de um tipo de política que envolve alianças e, sobretudo, a gestão das relações e dos processos. A mesma expertise funciona para advogados especializados em tribunais superiores. É justamente a experiência no tribunal que permite que realizem com maior precisão essa avaliação. Como afirmaram McAtee e McGuire (2007: 264), analisando a Suprema Corte dos Estados Unidos, um advogado com maior experiência na corte carrega maiores possibilidades de ganhar uma causa, persuadindo os juízes, do que aqueles com menos experiência. Essa "experiência" opera também nas temporalidades processuais, nos modos de gerência do tempo de propositura e de decisão de cada ação judicial. Muitas vezes, saber operar na dinâmica do tribunal é mais importante do que construir um argumento jurídico potente. Essa dinâmica envolve, como vimos, a relação entre os ministros e as temporalidades tradicionalmente observadas, mas também as dinâmicas próprias de cada causa a ser julgada, ou seja, o que passo a chamar de política dos processos.

\section{A POLÍTICA DOS PROCESSOS}

O que chamo aqui de "política dos processos" relaciona-se aos modos estratégicos de administração da economia processual, com vistas a garantir determinadas posições jurídicas. Destaco a ideia de que o que circula no tribunal através dos processos são causas jurídicas: uma mistura específica entre

8 Pelo regimento interno do tribunal, cada gabinete tem um chefe, bacharel em direito, cinco assessores também com formação em direito, dois assistentes judiciários com formação superior, além do quadro de funcionários comissionados, dos quais no mínimo três devem ser funcionários do tribunal. Além desses, existem funcionários terceirizados que realizam algumas tarefas sem previsão regimental. É comum que ministros com carreira docente em universidades tragam para formar o gabinete seus orientandos de pós-graduação. Existem também funcionários de confiança herdados de ministros que se aposentam. No entanto, é prerrogativa de cada ministro estruturar seu gabinete de acordo com seu próprio arranjo, apenas levando em consideração as normas regimentais. 
pessoas e coisas com reverberações, tendo em vista que os julgamentos do STF funcionam como orientação geral para qualquer caso semelhante ao que está sendo julgado. Riles (2003) sugere que no estudo das práticas jurídicas há de se observar a dinâmica entre dois gêneros fundamentais do direito, o instrumental e o expressivo. Conforme a autora, os atos legais e as interpretações jurídicas desenvolvem os dois gêneros em sequência. No gênero expressivo (que produz sentido, e, portanto, produz coisas), a produção de significado é temporalmente situada, "a expressão ou os sentidos da lei (definições) podem ficar datados, separados de seus objetos" (Onto 2015: 124).

A norma jurídica, quando vista a partir do gênero expressivo, é constituída com base na separação entre o objeto expresso e a realidade à qual se refere, e é exatamente por isso que a significação pode ser disputada. Seguindo Wagner, Riles (2003: 192) argumenta que os atos legais são "símbolos referenciais" que operam no contraste entre o símbolo e o que ele simboliza. No gênero instrumental, a questão principal está nos modos como o direito se torna ele mesmo objeto ou produz seus próprios objetos, que significam menos do que produzem efeitos. Existem, segundo Riles (2003: 192), dois tipos de objetificação: aquela que opera tornando a realidade objeto da técnica e, portanto, objetificando a realidade a partir de modelos racionalizados (Samuel 2004), e outra, a instrumental, que, ao invés de produzir uma separação entre a lei e o mundo por meio da criação de significados, torna-se ela mesma um objeto no mundo. ${ }^{9}$ Nessa medida, falar em políticas dos processos implica tomar o próprio processo como um objeto em constituição constante, no qual se articulam práticas, temporalidades e técnicas.

Antes de qualquer coisa, como já argumentei em outro lugar (Lewandowski 2014), uma decisão é efeito tanto das relações, como dos procedimentos administrativos produzidos por diversos setores do tribunal. Para os propósitos deste artigo, nos concentramos numa zona dessa trama: a relação entre os ministros e seus gabinetes.

A forma de administração carrega consigo o próprio conteúdo. Por isso, uma boa administração processual nos gabinetes leva em conta outros registros que não apenas o conteúdo da decisão em si. A avaliação dos processos e seus potenciais é realizada pelos gabinetes levando em conta as possibilidades de que determinada posição saia vencedora da votação plenária. De modo mais geral, um processo que não seja repetido - ou seja, que demande uma decisão extraordinária em plenário - quase nunca é julgado rapidamente pelo tribunal, pois existe um tempo necessário para sua maturação, que se relaciona a pelos menos três dimensões.

9 Riles parte da definição de Strathern, segundo a qual objetificação é “o modo pelo qual pessoas e coisas se tornam objeto do olhar subjetivo ou de sua criação” (Strathern apud Riles 2003: 198). 
A primeira delas diz respeito à própria posição de relator - como aquele que dirige o processo. A segunda diz respeito à administração do processo, realizada também pelas partes, através da entrega de documentos e respostas às intimações do tribunal. Finalmente, existe também uma ideia de que processos decididos muito rapidamente não são devidamente estudados e avaliados pelo tribunal. Essa última dimensão se relaciona ao que Latour (2010) descreveu como "sustentação da dúvida". Conforme o autor, a operação do direito e os procedimentos técnicos se voltam a sustentar uma "dúvida" pelo maior tempo possível, como garantia de que uma solução (a sentença) não foi precipitada, "arbitrária" ou "superficial" (Latour 2010: 221). Nessa medida, enquanto as pastas dos volumes dos autos processuais não estiverem amassadas, riscadas, quase a se desfazer - indicativos de que aquele processo passou pela mão de várias pessoas, foi revirado, visto e revisto -, o processo não estará pronto para ser julgado. Um processo com "substância" seria aquele que teria passado por várias mãos.

A gestão de um processo compõe aquilo que chamo de "política dos processos". A avaliação da melhor conjuntura para que uma decisão se efetive implica atentar para modos de avaliação do tempo da decisão. Essa dinâmica processual é melhor observada justamente nos experimentos judiciais que tentam provocar uma mudança na jurisprudência.

O momento adequado para propor uma mudança nos entendimentos já firmados pela corte está relacionado ao tempo dos ministros na corte, ao tempo da própria jurisprudência e certamente aos processos e seus advogados, na medida em que não se muda uma jurisprudência sem um processo cujo objeto demande que determinado precedente seja trazido ao debate. Caso não apareça no tribunal esse processo, uma jurisprudência terá vida longa. Para propor uma mudança seria preciso então avaliar todas essas dimensões, mensurando o risco de uma ação jurídica.

Conforme o ministro aposentado Sepúlveda Pertence: "Não se desafia uma jurisprudência que acabou de ser firmada. Tem de ir aos poucos, corroendo-a desde a base até tentar voltar à cúpula". Reverter desde a base significa operar uma desestabilização do precedente em tribunais de primeira e segunda instâncias, criando um tipo de pressão processual que chega ao STF por meio dos recursos julgados em última instância. Para operar uma reversão, cabe aos advogados a leitura da "conjuntura do tribunal", avaliada de acordo com as decisões mais recentes. Apresentar uma questão ao tribunal na conjuntura imprópria é um "risco" que evidentemente sempre existe, já que ninguém pode afirmar com certeza qual será o resultado de um julgamento. Ainda assim, pensa-se que é possível minimizá-lo caso se observe a conjuntura.

$\mathrm{O}$ risco refere-se justamente ao fato de que uma decisão da corte vincula, na maioria das vezes, todas as outras decisões similares em outros tribunais de instâncias inferiores, uniformizando a resposta para determinada questão. 
Até que chegue ao STF, uma questão jurídica será respondida de formas distintas pelos tribunais de primeira e segunda alçada, e isso favorece os interesses jurídicos de alguns advogados.

Contudo, é preciso observar que essa ideia de uniformização é também marcada por uma instabilidade, na medida em que os documentos produzidos pelo STF como decisões são usados pelos demais tribunais de modos distintos, ou seja, existe uma manipulação (e não estou conferindo sentido negativo, a princípio) da verdade processual, um manejo na direção que se queira dar, e é exatamente desse modo que as causas se movimentam.

A conjuntura do tribunal não apenas opera nas tentativas de mudar uma jurisprudência, mas também na propositura de uma ação. Narrando a trajetória de um de seus casos como advogado - tratava-se de questão que envolvia o monopólio dos correios -, o ministro Luís Roberto Barroso destacava o erro da propositura daquela ação: "era uma ação muito arriscada", dizia o ministro; "começar a discutir essa questão numa ação direta é jogar o jogo inteiro numa cartada só". ${ }^{10} \mathrm{O}$ que o ministro parece dizer é que administrar os riscos das decisões faz parte de um cálculo realizado tanto pelos juízes como por procuradores e advogados, especialmente quando se trata de processos que correm nos tribunais superiores.

A procuradora da República, representante do Ministério Público, que entrevistei durante a pesquisa também mencionou que cálculos processuais podem ser feitos de modo a potencializar as chances de o tribunal julgar favoravelmente uma questão apresentada. É importante destacar que se trata aqui, sobretudo, de questões entendidas como relevantes, e não de recursos corriqueiros.

"Os processos estratégicos, aqueles que você acha que têm um poder transformador, esses você calcula o tempo... Eu tenho uma questão que está aqui prontinha [apontava para estante da sala, mostrando uma pasta], só que eu tenho uma liminar favorável do ministro Ayres Brito; então, pra que eu vou submeter esse processo agora, com risco de perder? Eu preciso deixar que se criem fatos consumados. Todo mundo faz isso, os advogados fazem". ${ }^{11}$

Os processos julgados pelo plenário permitem aos ministros também uma análise dessa conjuntura do tribunal e do tempo de liberar um processo para julgamento. Assim como os advogados ou a Procuradoria, os ministros, em

10 Uma "ação direta de inconstitucionalidade" é um tipo de ação judicial que só pode ser apresentado no Supremo Tribunal Federal, como instância última e única. Ela funciona questionando diretamente um ato do poder público.

11 Entrevista realizada em 25 de setembro de 2012 na PGR. 
alguns casos, analisam as possibilidades de o plenário acompanhar um voto que será proferido. Esses cálculos todos são várias vezes incorporados à ideia de técnica jurídica, de expertise específica da prática de conhecimento, mas também de política.

A trajetória da ADPF 54 - referente à questão da possibilidade de aborto em casos de anencefalia -, relatada pelo ministro Marco Aurélio, é um bom exemplo dessa dinâmica. ${ }^{12}$ A petição que deu origem ao processo chegou ao STF em 2004, com pedido liminar. O pedido foi rapidamente liberado para entrar na pauta, o que não aconteceu, resultando então numa decisão monocrática que concedeu o pedido no dia anterior ao início do recesso forense. ${ }^{13} \mathrm{Ou}$ seja, o aborto em casos de anencefalia ficou liberado durante todo o recesso do tribunal. Na volta dos ministros, a liminar foi pautada para referendo e cassada pelo colegiado. O ministro relator decidiu então "segurar" o processo no gabinete.

"Quando cassaram a minha liminar, eu percebi que a concepção era contrária ao pano de fundo. Então coloquei o processo na prateleira, porque não envolvia interesses subjetivos. Quando o tribunal liberou as pesquisas com células-tronco, muito embora por um escore muito apertado de 6 a 5, eu entendi que era a hora, e o resultado foi muito satisfatório. Existe uma avaliação pelos precedentes, pelos enfoques realizados até então. Nós temos sempre um termômetro. Aí devemos atuar no campo político-institucional". ${ }^{14}$

A ADPF 54 foi julgada apenas em 2012, quase oito anos depois de ter sido apresentada. Na avaliação do ministro Marco Aurélio, caso fosse julgada antes disso, o resultado teria sido diferente. $\mathrm{O}$ tempo na prateleira, que ultrapassa o tempo procedimental, garantiu ao processo o resultado esperado por seu relator.

A liberação de um processo pelo relator não significa, portanto, que ele será prontamente pautado, já que existe aqui uma aposta de que os ministros não facilmente retrocedem em seus entendimentos e que um processo só deve ser pautado sob determinada configuração do plenário.

A rigor, a gerência da pauta, ou seja, a decisão que estabelece a ordem dos processos a serem julgados, é prerrogativa do presidente do tribunal. Os funcionários mais antigos e os ministros aposentados com quem pude conversar identificam que, nos últimos anos, os presidentes têm potencializado o poder

12 Uma ADPF, "arguição de descumprimento de preceito fundamental", é um tipo de ação, ajuizada exclusivamente no STF, que tem por objeto evitar ou reparar lesão a preceito fundamental resultante de ato do poder público.

13 Decisões monocráticas são aquelas tomadas por apenas um ministro do tribunal; podem ser decisões liminares ou mesmo decisões finais em processos entendidos como repetidos.

14 Entrevista realizada em maio de 2012. 
de pautar o tribunal, tornando a pauta um dos instrumentos dessa política dos processos. Conforme o ministro Sepúlveda Pertence, a pauta se tornou objeto da política do tribunal durante a presidência do ministro Nelson Jobim. ${ }^{15}$ Antes dele, segundo Pertence, a pauta obedecia à ordem de liberação dos processos pelos gabinetes, ainda que já existissem pedidos dos relatores para que determinado processo pudesse ser antecipadamente pautado. $\mathrm{O}$ ministro citado como aquele que institui a política da/na pauta é exatamente um dos poucos com experiência na política partidária; sua gestão como presidente do tribunal trouxe uma forma de se fazer política, agora convertida em estratégia processual, ainda que vez ou outra contestada no próprio tribunal.

Com o "poder de pautar", a presidência, caso imagine que seu entendimento não será acompanhado pela maioria, pode segurar o processo. Essa avaliação é feita pelo conjunto do gabinete e não apenas pelos ministros individualmente. A lógica de segurar ou liberar um processo é um instrumento que pode potencializar determinado resultado, ainda que não existam garantias. Outro critério que aparece na constituição da pauta são os processos considerados importantes para o presidente, que sendo julgados ficariam para a história como "legado" daquela gestão.

Se um processo levar anos para ser julgado, as situações a que ele se refere tornam-se "fatos consumados" e tornam qualquer decisão do tribunal sem efeito. Esses acontecimentos do mundo da vida têm pouca importância, porquanto uma causa jurídica não se configura a partir de interesses específicos dos sujeitos de um processo específico. Mesmo que o objeto do processo deixe de existir, ele pode voltar ao tribunal. Objetivamente, a causa é mais importante que as pessoas no STF, tendo em vista que o tribunal decide e aplica teses jurídicas com validade para mais de um caso específico. "Pautar um processo" ganha então quase a mesma importância da decisão, tendo em vista que, a depender do tempo do processo na fila para ser pautado, a decisão pode ter "se produzido sozinha".

Já no plenário existe a possibilidade do pedido de vistas, que também segura a decisão de um processo. Em grande parte das vezes, quando acompanhei as sessões, o pedido de vistas era feito quando havia um grande debate entre os ministros, evidenciando divergência entre os entendimentos e dúvidas além das que normalmente ocorrem em um julgamento. Nesses casos, algum ministro pedia vistas do processo para "estudar melhor os autos".

Outro cenário possível, e sempre aventado por alguns funcionários do tribunal, é o pedido de vistas para "ganhar tempo". Nesse caso, o ministro trancaria a decisão, ainda que a maioria já tenha sido formada (que a maior parte dos ministros já tenha votado), para tentar construir novos elementos que possam convencer os demais de seu entendimento. Tratar-se-ia então, nos termos de 
um de meus interlocutores, de "pura política". O retorno do processo ao plenário pode demorar anos, uma vez que depende da liberação do voto-vista (voto dado depois de um pedido de vistas de um processo) pelo ministro e da sua inclusão na pauta do tribunal.

Se o colegiado dissolve o poder individual dos ministros, a gestão processual consegue ditar o ritmo das decisões, e indiretamente, a própria decisão. Uma decisão não só é política, como objeto da política do tribunal. Desse modo, importa menos quão política pode ser uma decisão, no sentido de ser guiada por interesses não revelados, que suas condições de efetivação dentro do quadro de práticas aceitáveis pelo conjunto de operadores. Sempre existirá mais de uma resposta possível. Na medida em que a alquimia do processo decisório envolve teorias, ponderações, dispositivos e também tempo e negociação procedimental, o ritmo do processo também faz decisão.

\section{CONSIDERAÇÕES FINAIS}

Este artigo procurou descrever certas práticas e políticas de um tribunal específico. Nele tentei demostrar que as decisões são criações jurídicas e que sua estabilidade depende da capacidade dos agentes para se movimentarem (i) diante de um quadro de demandas e requisitos dirigidos ao mundo fora do direito, ao mesmo tempo em que (ii) operam uma política interna que diz menos respeito a uma agenda exterior ao tribunal do que à negociação intestina em torno de posições, causas e pessoas.

Os requisitos da prática jurídica dão sentido à própria prática e a diferenciam de outras. Todos os requisitos de atuação dos ministros e dos advogados evocam não só uma dimensão convencional, no sentido dado ao termo por Wagner (1981), como também, e ao mesmo tempo, a capacidade criativa de manusear os ritmos e temporalidades dos processos, permitindo que as coisas aconteçam. As posições dos ministros aparecem como modo de produção da transformação. No entanto, como essa transformação tem um movimento próprio que quase sempre a oculta, o momento dela é perdido. Todo o conjunto de formas e relações exige de cada operador do direito - seja ele ministro, advogado ou servidor - o enfrentamento de possibilidade de mudança e a gestão de teses jurídicas em conjunturas mais ou menos complexas, tanto inefáveis quanto perenes. A disputa e as relações entre os ministros operam uma exibição controlada do dissenso, tendo em vista que qualquer atuação fora de alguns limites mais ou menos esperados, isto é, já experimentados, pode inviabilizar os alinhamentos necessários.

Com efeito, a decisão final - a res judicata, ou a coisa julgada, expressão do direito romano - tornaria definitiva uma decisão apenas para um processo. As mesmas pessoas, no mesmo tipo de processo, com o mesmo objeto, não podem reivindicar uma nova análise ou uma nova decisão. Isso não quer dizer que o 
objeto jurídico do processo seja indiscutível, ao contrário, a ilusão de que o processo acabou indica justamente já estarem em curso os movimentos processuais de desgaste e revitalização das causas e teses jurídicas.

A decisão é efeito do tempo em dois sentidos. Tendo em vista que não se pode discutir eternamente um processo, termina por tomar por verdade alguma coisa possível. Por outro lado, as temporalidades processuais marcam a decisão e a orientam, na medida em que são atravessadas por uma política que está na estética das relações, nos usos e estratégias processuais que mobilizam os ministros e seus gabinetes em torno de suas posições.

A ideia de política ganha aqui um contorno específico, que se relaciona, mas não se resume, aos sentidos estabelecidos no debate sobre judicialização e/ou politização do judiciário. Qualquer decisão, por ser decisão, é política. No entanto, por meio dos caminhos de um processo amalgamados com as trajetórias dos ministros e de suas posições, vemos que as formas como se faz e se opera uma política nos tribunais revela estratégias de direcionamento da verdade e nunca o fim do debate pelo estabelecimento definitivo da verdade. Esse tipo de verdade alcançada através de um processo jurídico é ela mesma a forma aparente da disputa entre vários outros elementos que, como tentei demonstrar, colocados juntos são capazes de revelar tanto os meios quantos os fins de uma decisão judicial, ou seja de um lado o que se chama de política, de outro aquilo que é nomeado como técnica.

\section{BIBLIOGRAFIA}

ALMEIDA, Frederico N. Ribeiro de, 2010, A Nobreza Togada: As Elites Jurídicas e a Política da Justiça no Brasil. São Paulo, Universidade de São Paulo, dissertação de mestrado.

LATOUR, Bruno, 2010, The Making of Law: An Ethnography of the Conseil d'Etat. Paris, La Découverte/Poche.

LEWANDOWSKI, Andressa, 2014, O Direito em Última Instância: Uma Etnografia do Supremo Tribunal Federal. Brasília, Universidade de Brasília, tese de doutorado.

McATEE, Andrea, e Kevin T. McGUIRE, 2007, "Lawyers, justices, and issue salience: when and how do legal arguments affect the US Supreme Court?", Law \& Society Review, 41 (2): 259-278.

McLACHLIN, Beverley, 2000, "Judicial power and democracy", Singapore Academy of Law Journal, 12: 311 1-330.

MELlO, Celso, 2012, Notas sobre o Supremo Tribunal (Império e República). Brasília, Supremo Tribunal Federal, recurso eletrônico disponível em $<$ http://www.stf.jus.br/arquivo/cms/ publicacaoPublicacaoInstitucionalCuriosidade/anexo/Notas_informativas_sobre_o_ STF_versao_de_2012.pdf > (3. ${ }^{a}$ edição, última consulta em junho de 2019). 
ONTO, Gustavo, 2015, "Mercado relevante: uma perspectiva etnográfica”, em E.C. Mendonça, F.L. Gomes e R.P.A. Mendonça (orgs.), Compêndio de Direito da Concorrência: Temas de Fronteira. Ribeirão Preto, Editora Migalhas, 119-144.

POTTAGE, Alain, 2004, "Introduction: the fabrication of persons and things", em A. Pottage e Martha Mundy, Law, Anthropology, and the Constitution of the Social: Making Persons and Things. Cambridge, Cambridge University Press, 1-39.

POTTAGE, Alain, 2012, “The materiality of what?", Journal of Law and Society, 39 (1): 167 $-183$.

RILES, Annelise, 2003, "Law as object”, em S. E. Merry e D. Brenneis (orgs.), Law \& Empire in the Pacific: Fiji and Hawai'i. Santa Fe, NM, School of American Research Press, 187-212 .

SAMUEL, Geoffrey, 2004, "Epistemology and comparative law: contributions from the sciences and social sciences", em M.V. Hoecke (org.), Epistemology and Methodology of Comparative Law. Oxford, Hart Pub, 35-77.

SOUZA, Larissa Maria Melo, 2012, A Fábrica de Argumentos: Uma Etnografia da Construção da Iniquidade nos Casos da Anistia pelo Supremo Tribunal Federal. Brasília, Uniceub, dissertação de mestrado.

STENGERS, Isabelle, 1996, Cosmopolitiques: Tome I - La Guerre des Sciences. Paris, La Découverte/Les empêcheurs de tourner en rond.

STENGERS, Isabelle, 2005, "Notes on an ecology of practices", Cultural Studies Review, 11 (1): 183-196.

STRATHERN, Marilyn, 1991, Partial Connections. Savage, MD, Rowman \& Littlefield.

TATE, C. Neal, e Torbjorn VALlindER, 1995, The Global Expansion of Judicial Power. Nova Iorque, New York University Press.

WAGNER, Roy, 1981, The Invention of Culture. Chicago, The University of Chicago Press (ed. revista e ampliada).

Receção da versão original / Original version

Receção da versão revista / Revised version

Aceitação / Accepted
2016/09/15

$2017 / 12 / 11$

$2018 / 04 / 10$ 